\title{
GIS modeling of seismic vulnerability of residential fabrics considering geotechnical, structural, social and physical distance indicators in Tehran using multi-criteria decision-making techniques
}

\author{
F. Rezaie and M. Panahi \\ Department of Geophysics, Young Researchers and Elites Club, North Tehran Branch, Islamic Azad University, Tehran, Iran
}

Correspondence to: F. Rezaie (rezaiee.1984@gmail.com)

Received: 25 July 2014 - Published in Nat. Hazards Earth Syst. Sci. Discuss.: 12 September 2014

Revised: 7 January 2015 - Accepted: 3 February 2015 - Published: 9 March 2015

\begin{abstract}
The main issue in determining seismic vulnerability is having a comprehensive view of all probable damages related to earthquake occurrence. Therefore, taking into account factors such as peak ground acceleration at the time of earthquake occurrence, the type of structures, population distribution among different age groups, level of education and the physical distance to hospitals (or medical care centers) and categorizing them into four indicators of geotechnical, structural, social and physical distance to needed facilities and from dangerous ones will provide us with a better and more exact outcome. To this end, this paper uses the analytic hierarchy process to study the importance of criteria or alternatives and uses the geographical information system to study the vulnerability of Tehran to an earthquake. This study focuses on the fact that Tehran is surrounded by three active and major faults: Mosha, North Tehran and Rey. In order to comprehensively determine the vulnerability, three scenarios are developed. In each scenario, seismic vulnerability of different areas in Tehran is analyzed and classified into four levels: high, medium, low and safe. The results show that, regarding seismic vulnerability, the faults of Mosha, North Tehran and Rey make, respectively, 6, 16 and $10 \%$ of Tehran highly vulnerable, while 34,14 and $27 \%$ is safe.
\end{abstract}

\section{Introduction}

The Iranian plateau is located between two plates of Eurasia and Arabia as a part of the Alpine-Himalayan orogenic belt and is among the world's most active seismic areas. Tectonic activities in this scope are the result of northward Arabian plate movement towards Eurasia and reveal the convergence of these two plates (Berberian, 1981; Hessami et al., 2001; Allen et al., 2004). GPS studies show that the Arabian plate is moving about from 21 to $25 \mathrm{~mm}$ northward each year (Sella et al., 2002; Vernant et al., 2004). The result of this movement on the Iranian plateau is varied due to the existence of different geological structures in different locations (Hessami et al., 2006), such that the amount of movement is up to $18 \mathrm{~mm}$ per year in the Makran subduction zone and $8 \mathrm{~mm}$ in Koppeh Dagh. There are also westward movements of about $8 \mathrm{~mm}$ per year in the Zagros and Alborz mountains (Fu et al., 2007). These overall movements have created heavy physical and financial damages to the area. An example is the Bam earthquake (2003, $\left.M_{\mathrm{w}}=6.6\right)$ which left over 30000 killed, 10000 injured, 100000 homeless and devastated more than $80 \%$ of houses (National Report of the Islamic Republic of Iran on Disaster Reduction, 2005). Statistically, it can also be stated that during the last 100 years, the Iranian plateau has experienced 14 major earthquakes with the magnitude of 7 (on Richter scale) and 51 earthquakes with the magnitude of 6 to 7. Earthquakes in Buin-Zahra $\left(1962, M_{\mathrm{s}}=7.3\right)$, Dashte Bayaz $\left(1968, M_{\mathrm{s}}=7.3\right)$, Tabas $\left(1978, M_{\mathrm{S}}=7.8\right)$, Sirch $\left(1981, M_{\mathrm{S}}=7.3\right)$ and Manjil $\left(1990, M_{\mathrm{S}}=7.7\right)$ are some such examples (Mahdi and Mahdi, 2013). 
Greater Tehran (Iran's capital) has a population of around 12 million people. As a result of the city being located in the vicinity of three active faults, the Mosha, North Tehran and Rey faults, it has high seismic vulnerability potential. The study of the earthquakes' catalogs proves this claim. Therefore, developing an earthquake vulnerability map for Tehran is of utmost importance.

Since several factors determine the seismic vulnerability of a city and all of them have to be studied simultaneously, multi-criteria decision-making (MCDM) techniques can be used in order to fill this gap. MCDM follows a collection of methods through which techniques and algorithms utilized to solve complex decision-making covering a wide range of choices and assessed by multiple, conflicting and incommensurable criteria as well as developing, assessing and prioritizing of decision-making alternatives can be used (Malczewski, 1999; Suárez-Vega et al., 2011). Since geographical information system (GIS) facilitates vulnerability studies and natural hazards analysis as a useful tool for managing, controlling, processing and analyzing the spatial data (Rashed and Weeks, 2003; Gamper et al., 2006; Almasri, 2008), utilizing GIS-based multi-criteria decisionmaking (GIS-MCDM) developed by Malczewski (2006) provides the possibility of prioritizing and combining the spatial criteria from different location and description viewpoints and eventually making comprehensive decisions. Different GIS-MCDM techniques are available depending on the required operations in order to acquire the final assessment from alternative solutions; analytic hierarchy process (AHP) is one of them.

AHP is one of the most comprehensive algorithms developed for decision-making with multi-criteria because it allows for hierarchically formulizing the complex problems; there is also the possibility of considering different quality and quantity criteria simultaneously (Chen et al., 2008). Thus, for solving complex spatial problems the combination of AHP with GIS resolves many issues. As a result, a great body of research has been conducted to assess the vulnerability of cities to natural events including earthquake via AHP and GIS, among which Chen et al. (2001), Rashed and Weeks (2003), Cutter et al. (2003), Servi (2004), Ebert et al. (2009), Schmidtlein et al. (2008), Botero Fernández (2009) and Nefeslioglu et al. (2013) are only examples.

This study takes into account three seismic scenarios for the faults of the Mosha, North Tehran and Rey in order to assess the seismic vulnerability of Tehran. To this end, not only the geotechnical index but also a review of the literature, expert opinions and the experience of past earthquakes in Iran, other influential factors in seismic vulnerability of cities including the type of structures, population distribution in different age groups, level of education and distance to road network (further categorized in three indicators: structural, social, and physical distance to needed facilities and distance from dangerous ones) are taken into account. Each of these criteria (indicators) is divided into alternatives (sub- indicators). In the next step, to get the weight of each criterion or alternative, AHP and pairwise comparison of criteria and alternatives are used. Then, using GIS, the criteria or alternatives are combined regarding the gained weight. Finally, three seismic vulnerability maps are developed for Tehran based on three possible earthquakes resulting from the activity of each aforementioned fault.

\section{The study area}

Tehran lies at latitudes $51^{\circ} 15^{\prime}$ and $51^{\circ} 35^{\prime} \mathrm{E}$ and longitudes $35^{\circ} 33^{\prime}$ and $35^{\circ} 50^{\prime} \mathrm{N}$. The city has experienced a major wave of migration due to economic, welfare and cultural issues during the last 3 decades. The metropolitan's population has increased from around 11 million in 2006 to 12 million in 2011 (average growth of 1.44 per year) (Seifolddini and Mansourian, 2014). Tehran officials have taken many factors into consideration in addition to the population and divided the city into 22 districts to provide better services to the citizens. Tehran is located in the southern foothills of the Alborz mountain range in the vicinity of three active faults, Mosha, North Tehran and Rey, that make the city seismically a matter of concern. The analysis of the earthquakes up to $100 \mathrm{~km}$ away (Fig. 1a and b) shows the seismic status of the scope.

As the catalogs of earthquakes and seismotectonic studies show, earthquake occurrences in Tehran are partly the result of movement on three active faults.

1. The Mosha Fault, first described as a reverse fault dipping north by Berberian et al. (1985) and Tchalenko et al. (1974), is $\sim 175 \mathrm{~km}$ long at the southern edge of the Alborz mountains. The Mosha Fault is composed of three segments with slightly different orientations (Landgraf et al., 2009). The strike of this fault changes in the western segment from $\sim \mathrm{EW}$ to WNW-ESE in the central segment. The eastern segment strikes WNWESE (Tatar et al., 2012) and has left-lateral motion along a north-dipping plane (Allen et al., 2004; Bachmanov et al., 2004) but with a slight normal component (Ritz et al., 2006). The Mosha has been the cause of big historical earthquakes with magnitudes of over 6.5 in AD $958\left(M_{\mathrm{s}} \sim 7.7\right)$, AD $1665\left(M_{\mathrm{s}} \sim 6.5\right)$ and $\mathrm{AD} 1830$ $\left(M_{\mathrm{s}} \sim 7.1\right)$ (Berberian and Yeats, 2001).

2. The North Tehran Fault is composed of faults which lie north and west of Tehran with an estimated length of $110 \mathrm{~km}$ (Tchalenko et al., 1974; Berberian et al., 1985). The strike of the eastern part of the fault is ENE-WSW and dips northward, and the western part is NW-SE. The dip of this fault is between 10 and $80^{\circ}$. The focal mechanism of the North Tehran Fault is thrust with a component of left-lateral strike-slip motion (Nazari, 2006). Since the North Tehran Fault is a seismically active fault, it is probable that the historical earthquakes with the magnitude of $M_{\mathrm{S}} \sim 7.1$ and $M_{\mathrm{s}} \sim 7.3$ during 

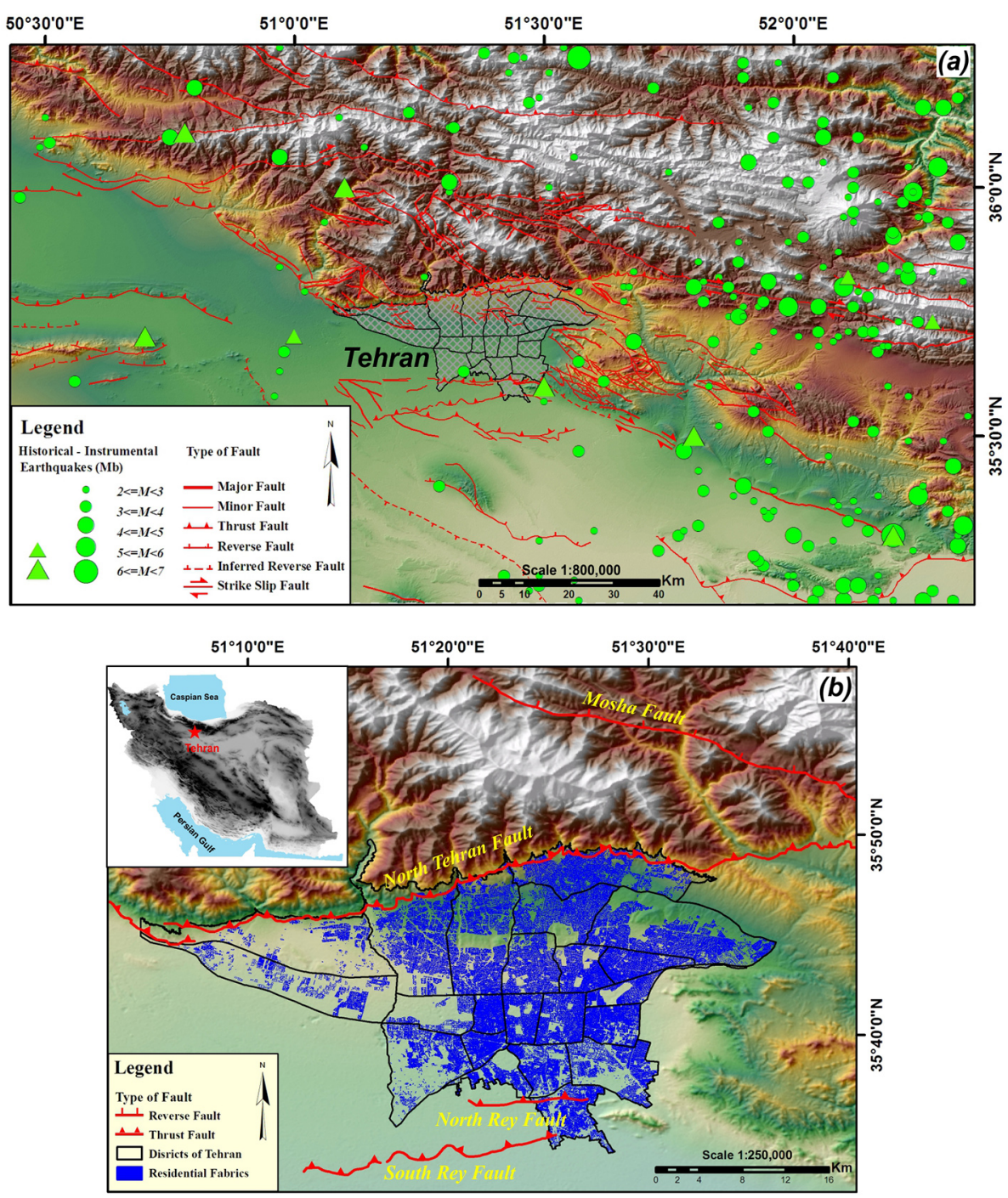

Figure 1. The study area and the distribution of historical and instrumental earthquakes up to $100 \mathrm{~km}$ away from Tehran.

$855-856$ (exact year is uncertain) and 1177 , respectively, occurred due to ruptures of this fault (Ashtari Jafari, 2010).

3. The faults of North and South Rey, named originally by Berberian et al. (1985), are 20 and $16.5 \mathrm{~km}$, respectively. They are 3 to $5 \mathrm{~km}$ away from each other. Since the eastern and western strikes of these faults are buried under the young fluvial sediments, their dip is unrecognizable from the ground; however, the geometric shape of it on the ground shows north-dipping thrust faults. According to the studies conducted by Berberian and Yeats $(1999,2001)$, the occurrence of the historical earthquakes of $855\left(M_{\mathrm{s}} \sim 7.1\right), 864\left(M_{\mathrm{s}} \sim 5.3\right), 958$ $\left(M_{\mathrm{s}} \sim 7.7\right)$ and $1177\left(M_{\mathrm{s}} \sim 7.2\right)$ could be the result of these faults' movements.
Due to the high seismic activity rate and the high probability of earthquakes occurring with high magnitude in Tehran on one hand, and the density of structures, violation of construction codes and standards, improper distribution of services and facilities as well as dense population in some parts on the other hand, the city has increased seismic vulnerability. Therefore, developing a vulnerability map of earthquakes for Tehran in order to identify the vulnerable and safe areas in the city and suitably plan to prevent or decrease the potential effects of earthquake occurrence is of utmost importance.

\section{Methodology and data analysis}

\subsection{Indicators}

Since the purpose of this study is to investigate the vulnerability against earthquakes with a comprehensive viewpoint, 


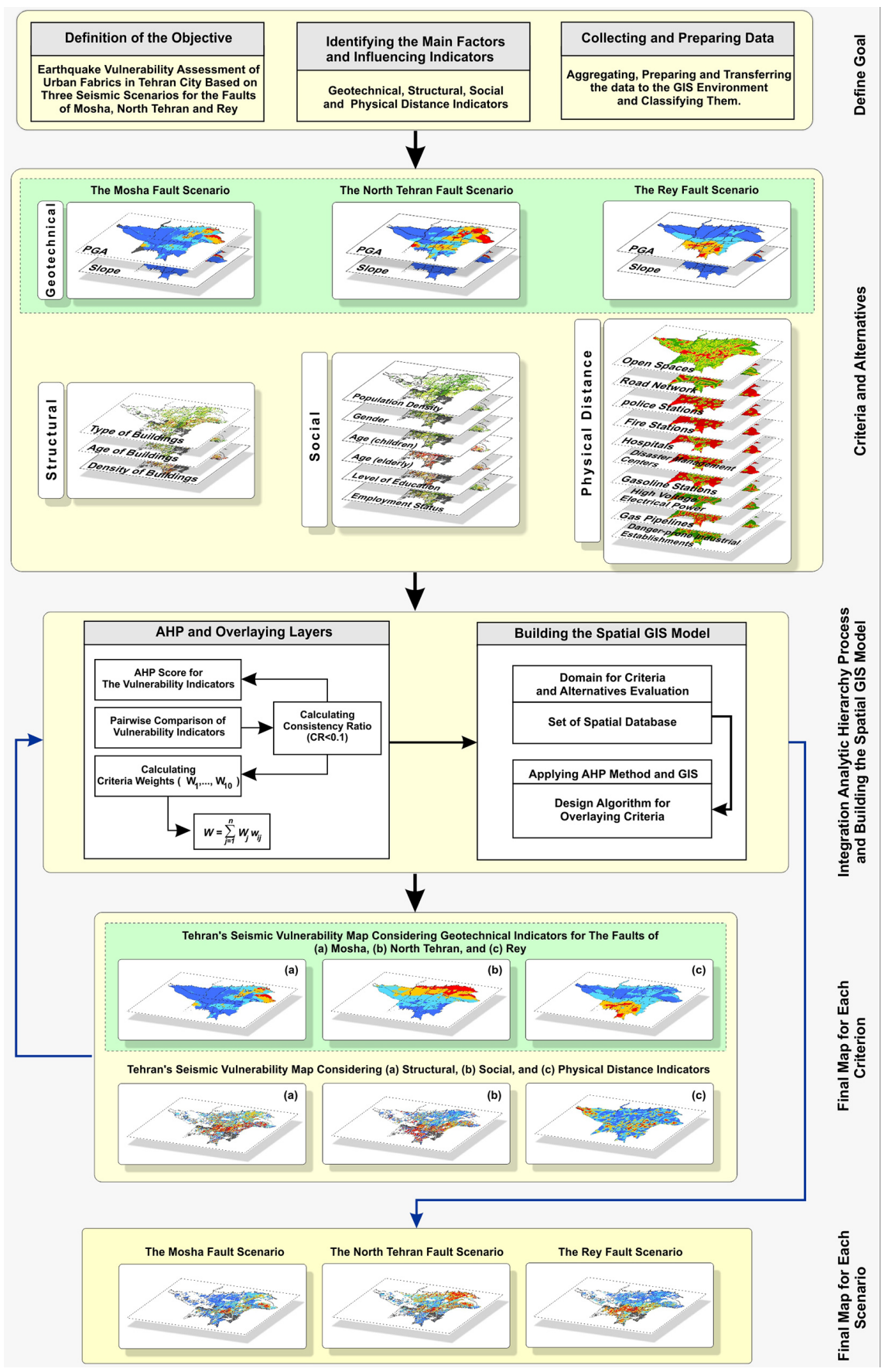

Figure 2. The process of seismic vulnerability assessment using AHP technique.

seismic vulnerability must be studied by taking all influential factors into account (Fig. 2). Thus, after reviewing the literature, regulations, viewpoints and experiences of experts and taking the available data for influential indicators including geotechnical, structural, social and physical distance from needed facilities and away from dangerous ones into consideration for each residential fabric in census units (Fig. 1b), the main sub-indicators are extracted as follows.

\subsubsection{Geotechnical indicators}

One of the main and most influential factors that increases a city's vulnerability during an earthquake can be the geotechnical features of the scope. By studying and investigating the geotechnical specifications of an area we can gain useful data on the occurrence of an earthquake and its magnitude as well as spatial data on affected areas. The acceleration due to strong ground motion at each site depends 
on a complex combination of the earthquake's magnitude, duration, frequency content, the distance between the earthquake's hypocenter and site, soil condition in the scope, etc. Thus, one of the important criteria while designing the structures, and also one of the main reasons for the building damages, is the peak ground acceleration (PGA) while an earthquake occurs (Ghodrati Amiri et al., 2010; Babayev et al., 2010; Armaş, 2012; Moradi et al., 2013; Panahi et al., 2014). In Iran, the peak ground acceleration which had destroyed or damaged the structures was $0.1 \mathrm{~g}$ (during the Golbaf earthquake in 1981) and about $1 g$ during the Zanjiran (1994) and Bam (2003) earthquakes (Jafargandomi et al., 2004). Surface slope is another geotechnical factor that must be taken into consideration since it is one of the influential factors in the instability of steep slopes and landslide occurrence in alluvial and sand soil, especially under a structure's foundation, while an earthquake occurs (Keefer, 1984; Plafker and Galloway, 1989; Harp and Wilson, 1995; Jibson et al., 2000; Lee and Talib, 2005; Lee and Pradhan, 2006; Jibson, 2007; Mahdavifar et al., 2002; Safari and Moghimi, 2010; Sarvar et al., 2011). This issue can lead to destruction and an increase in damages.

\subsubsection{Structural indicators}

Regarding the fact that many structures in Tehran are quite old and constructed by traditional methods, and also because most newly constructed structures have violated the construction codes and regulations (BHRC, 2005) and there has been inconsistent application of building regulations, the structures are quite vulnerable to earthquakes. This is made clear by a glimpse at the earthquakes which have happened over the last few decades in Iran. Therefore, considering the studies done and regarding the limitation of accumulated data in Tehran, using structural factors such as types of buildings per census unit (structure and building materials), age of buildings and density of buildings per census unit can have a determining role on seismic vulnerability (Tavakoli and Tavakoli, 1993; JICA and CEST, 2000; Cutter et al., 2003; Chakraborty et al., 2005; Ebert and Kerle, 2008; Ghayamghamian and Khanzade, 2008; Ebert et al., 2009; Lantada et al., 2009; Ishita and Khandaker, 2010; Şen, 2010; Alinia and Delavar, 2011; Martins et al., 2012; Armaş, 2012; Panahi et al., 2014).

\subsubsection{Social indicators}

Demographic context of a society during an earthquake occurrence or after is very important since these factors have a direct relationship with the increase or decrease in tolls and facilitation of relief operations. Unfortunately, during recent years earthquake experts have not paid enough attention to this issue and not enough studies have been conducted with this viewpoint on the last earthquakes. To resolve this, we studied seismic vulnerability articles with population as the main issue; the main sub-indicators extracted are as follows:

1. population density (Chakraborty et al., 2005; BacBronowicz and Maita, 2007; Ishita and Khandaker, 2010; Martins et al., 2012; Peng, 2012; Armaş and Gavriş, 2013),

2. gender (Fothergill, 1996; Granger et al., 1999; Fordham, 2000; Wisner, 2003; Cutter et al., 2003; Haki et al., 2004; Armaş, 2012; Martins et al., 2012),

3. age (children) (King and MacGregor, 2000; Cutter et al., 2003; Dwyer et al., 2004; Steinführer and Kuhlicke, 2007; Birkmann et al., 2008; Holand et al., 2011; Kuhlicke et al., 2011; Armaş, 2012),

4. age (elderly) (King and MacGregor, 2000; Cutter et al., 2003; Dwyer et al., 2004; Steinführer and Kuhlicke, 2007; Thieken et al., 2007; Birkmann, 2007; Reid et al., 2009; Flanagan et al., 2011; Holand et al., 2011; Åström et al., 2011; Rocklöv et al., 2011; Armaş, 2012; Zebardast, 2013),

5. level of education (Buckle, 2000; Cutter et al., 2003; Adger et al., 2004; Haki et al., 2004; Velasquez and Tanhueco, 2005; Schneiderbauer, 2007; Ebert and Kerle, 2008; Holand et al., 2011; Kuhlicke et al., 2011; Armaş, 2012; Martins et al., 2012),

6. employment status (Dwyer et al., 2004; Haki et al., 2004; Bac-Bronowicz and Maita, 2007; Ebert and Kerle, 2008; Holand et al., 2011; Kuhlicke et al., 2011; Zebardast, 2013).

\subsubsection{Indicator of physical distance to needed facilities and away from dangerous facilities}

One of the infrastructural influential factors in cities is the access of residential and populated areas to medical care facilities, open spaces, road networks, etc. Studies show that in urban societies not all residents have equal access to urban facilities and there may be great differences between the distribution of facilities in different areas of the city based on socioeconomic characteristics of residential areas, unplanned development of the cities, etc. Simultaneously, we can refer to unequal distribution of dangerous facilities inside dense urban fabrics such as gasoline stations, dangerous industrial establishments and high-voltage electrical power transmission lines; all these reasons lead to an increase in vulnerability and financial and physical tolls while an earthquake occurs. Therefore, with comprehensive and long-term planning to properly locate the urban structures and dangerous facilities, a city's vulnerability can be decreased significantly. In this paper, regarding the importance of access to needed facilities and distance from dangerous ones, 10 factors are into account to investigate the seismic vulnerability 
Table 1. Scale of preference between two parameters in AHP (Saaty, 1977).

\begin{tabular}{|c|c|c|}
\hline $\begin{array}{l}\text { Intensity of } \\
\text { importance }\end{array}$ & $\begin{array}{l}\text { Degree of } \\
\text { preference }\end{array}$ & Explanation \\
\hline 1 & Equally & Two factors contribute equally to the objective \\
\hline 3 & Moderately & Experience and judgment slightly to moderately favor one factor over another \\
\hline 5 & Strongly & Experience and judgment strongly or essentially favor one factor over another \\
\hline 7 & Very strongly & A factor is strongly favored over another and its dominance is showed in practice \\
\hline 9 & Extremely & The evidence of favoring one factor over another is of the highest degree possible \\
\hline $2,4,6,8$ & Intermediate & Used to represent compromises between the preferences in weights $1,3,5,7$ and 9 \\
\hline Reciprocals & Opposites & Used for inverse comparison \\
\hline
\end{tabular}

Table 2. Random inconsistency indices (RI) for $n=1,2, \ldots, 12$ (Saaty, 1980, 2000).

\begin{tabular}{lrrrrrrrrrrrr}
\hline$N$ & 1 & 2 & 3 & 4 & 5 & 6 & 7 & 8 & 9 & 10 & 11 & 12 \\
\hline RI & 0.00 & 0.00 & 0.58 & 0.90 & 1.12 & 1.24 & 1.32 & 1.41 & 1.45 & 1.49 & 1.52 & 1.54 \\
\hline
\end{tabular}

of Tehran: accessibility and distance to open spaces (parks and barren areas), road networks, police stations, fire stations, hospitals and disaster management centers and distance from gasoline stations, high-voltage electrical power transmission lines, gas pipelines and danger-prone industrial establishments (Rashed and Weeks, 2003; Servi, 2004; Altan et al., 2004; Hellström, 2007; Ebert and Kerle, 2008; Hizbaron et al., 2011; Armaş, 2012; Nan and Hong, 2013).

\subsection{Methodology}

The combined method of GIS-AHP is a suitable tool for spatial issues including seismic vulnerability of cities. A range of qualitative and quantitative indicators must be taken into account to investigate the seismic vulnerability of an area; as Fig. 2 shows, one of the main steps to realize this goal is using AHP to consider the indicators simultaneously with regard to the importance of each and using GIS to manage, integrate and analyze the data.

AHP, originally introduced by Saaty (1977), is a multicriteria decision-making technique. AHP is a weighted linear summation method in which the weight is gained through pairwise comparison of elements in a level of decisionmaking. AHP allows the decision-makers to change a complex problem to a hierarchical structure by identifying the elements of decision-making such as goal, criteria (indicators) and alternatives (sub-indicators), prioritizing and relating them to each other and simplifying the analysis and decision-making. Generally, AHP has three stages:

1. developing a tree structure for indicators and subindicators

2. pairwise comparison of indicators and sub-indicators and identifying the weight of each

3. estimation of consistency between judgments and weights.
With AHP, after identifying the influential indicators and sub-indicators (Fig. 2) for determining the weight of each factor, a systematic and structured comparison is used. This kind of comparison reduces the conceptual complexity of the problem under investigation; furthermore, the weight of each factor is determined regarding its level of importance, as shown in Table 1 and introduced by Saaty (1977). In other words, in AHP, weights show the dominance and intensity of importance of each factor in relation to the others in a hierarchical structure.

The most important issue in AHP and weighting the factors is the consistency between judgments and weights. In order to determine this, consistency index (CI) is used as defined by Saaty (2000):

$\mathrm{CI}=\frac{\lambda_{\max }-N}{N-1}$,

where $\lambda_{\max }$ is the largest or principal eigenvalue of the pairwise comparison matrix and $N$ is the order of the matrix. Saaty (1980) has identified the average random consistency index (RI) according to Table 2 and calculated the consistency ratio (CR) as follows:

$\mathrm{CR}=\frac{\mathrm{CI}}{\mathrm{RI}}$.

If $\mathrm{CR}=0$, the pairwise comparison matrix is completely consistent, and if CR $>0.1$, the matrix is inconsistent and pairwise comparison must be repeated between indicators and sub-indicators.

The final weight is gained by linear adding of given weights to indicators and sub-indicators (according to Eq. 3) and overlaying weighted raster layers.

$W=\sum_{j=1}^{n} W_{j} w_{i j}$ 
Table 3. Pairwise comparison matrix, sub-indicator weights and consistency ratio of the data layers.

\begin{tabular}{|c|c|c|c|c|c|c|c|}
\hline Sub-indicators & 1 & 2 & 3 & 4 & 5 & 6 & Weights \\
\hline \multicolumn{8}{|l|}{ Geotechnical } \\
\hline (1) Slope & 1 & & & & & & 0.250 \\
\hline (2) PGA & 3 & 1 & & & & & 0.750 \\
\hline \multicolumn{8}{|l|}{ Consistency ratio: 0} \\
\hline \multicolumn{8}{|l|}{ Structural } \\
\hline (1) Density of buildings & 1 & & & & & & 0.122 \\
\hline (2) Age of buildings & 3 & 1 & & & & & 0.320 \\
\hline (3) Type of buildings & 4 & 2 & 1 & & & & 0.558 \\
\hline \multicolumn{8}{|l|}{ Consistency ratio: 0.009} \\
\hline \multicolumn{8}{|l|}{ Social } \\
\hline (1) Employment status & 1 & & & & & & 0.0733 \\
\hline (2) Level of education & 1 & 1 & & & & & 0.1063 \\
\hline (3) Gender & 2 & 1 & 1 & & & & 0.1183 \\
\hline (4) Age (elderly) & 3 & 2 & 2 & 1 & & & 0.1999 \\
\hline (5) Age (children) & 3 & 2 & 2 & 1 & 1 & & 0.1999 \\
\hline (6) Population density & 4 & 2 & 2 & 2 & 2 & 1 & 0.3022 \\
\hline \multicolumn{8}{|l|}{ Consistency ratio: 0.021} \\
\hline \multicolumn{8}{|c|}{ Physical distance to needed facilities } \\
\hline (1) Disaster management center & 1 & & & & & & 0.064 \\
\hline (2) Hospital & 2 & 1 & & & & & 0.109 \\
\hline (3) Fire stations & 2 & 1 & 1 & & & & 0.126 \\
\hline (4) Police stations & 3 & 2 & 1 & 1 & & & 0.202 \\
\hline (5) Road network & 3 & 2 & 2 & 1 & 1 & & 0.223 \\
\hline (6) Open spaces & 4 & 3 & 3 & 1 & 1 & 1 & 0.272 \\
\hline Consistency ratio: 0.020 & & & & & & & \\
\hline
\end{tabular}

Physical distance from dangerous facilities

(1) High-voltage electrical power transmission lines

(2) Gas pipelines

$\begin{array}{ll}1 & 1 \\ 1 & 1\end{array}$

0.147

(3) Gasoline stations

(4) Danger-prone industrial establishments

$\begin{array}{lll}2 & 2 & 1\end{array}$

0.163

Consistency ratio: 0.006

Table 4. Pairwise comparison matrix, indicator weights and consistency ratio of the data layers.

\begin{tabular}{lrrrrr}
\hline Indicators & 1 & 2 & 3 & 4 & Weights \\
\hline Physical distance & 1 & & & & 0.150 \\
Social & 1 & 1 & & & 0.200 \\
Structural & 2 & 1 & 1 & & 0.282 \\
Geotechnical & 3 & 2 & 1 & 1 & 0.368 \\
Consistency ratio: 0.027 & & & & & \\
\hline
\end{tabular}

where $W$ shows the weight of each pixel in the vulnerability map, $W_{j}$ shows the normalized weight of each indicator, $w_{i j}$ is the weight of the $i$ th sub-indicator with respect to the $j$ th indicators and $n$ is the total influential indicators.

\section{Results}

Using AHP and determining the importance of each used sub-indicator and indicator in the study, with respect to four main indicators (Tables 3 and 4), the results (Figs. 3 and 4) are as follows.

\subsection{Geotechnical indicators}

Analysis of seismic vulnerability conducted according to geotechnical viewpoint over the entirety of Tehran shows that proximity of the Mosha Fault to the north and northeast of Tehran (located at a distance of about $36 \mathrm{~km}$ from the northeastern part of the city) and its intersection with the North Tehran Fault has put Tehran in the vicinity of the seismic zone of the fault. Other studies reveal that if the Mosha 

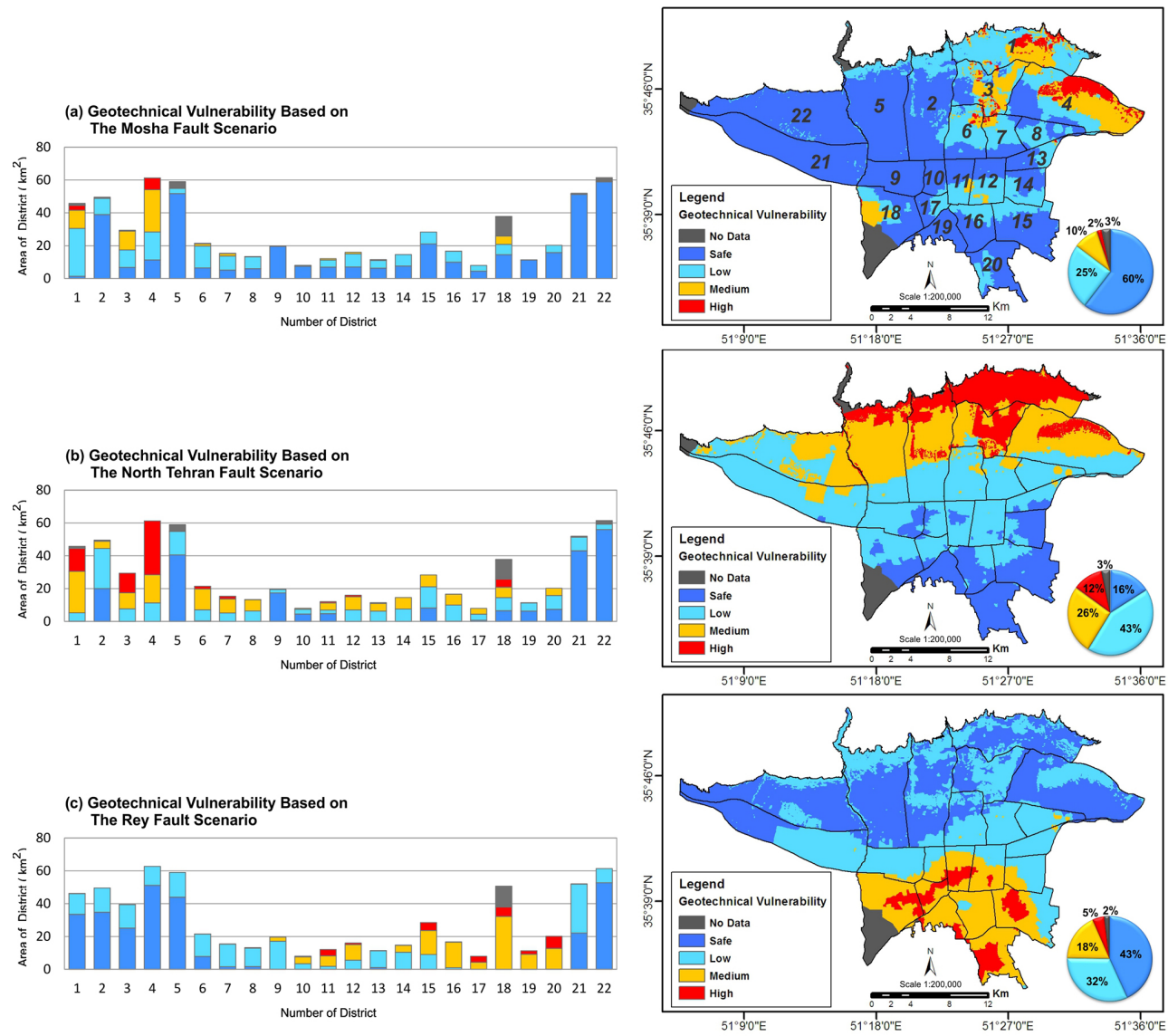

Figure 3. Tehran's seismic vulnerability map considering geotechnical indicator for the faults of (a) Mosha, (b) North Tehran and (c) Rey.

Fault becomes more active, Tehran will experience the PGA of $200 \mathrm{~g}$ (JICA and CEST, 2000). According to Fig. 3a, if an earthquake occurs as a result of this fault's movement, the geotechnical vulnerability in parts of districts $4,1,3,6$ and 7 ( $2 \%)$ will be high due to their vicinity to the fault. Nonetheless, $60 \%$ of Tehran will be safe.

Since the North Tehran Fault passes through all northern districts of Tehran, and a part of residential structures in districts 1,3 and 4 are constructed on it or its hanging wall, these areas are prone to direct disruption of the earthquake fault. The investigations show in the case of activity at this fault, the amount of PGA in the northern area will be around $400 \mathrm{~g}$. The more we move towards the south, the more the PGA decreases due to distance from the source of earthquake, reaching around $200 \mathrm{~g}$ (JICA and CEST, 2000). Studies also show that the slope changes from 30 to $0^{\circ}$ from north towards south. This makes structures in the northern areas more instable. Therefore, according to Fig. $3 \mathrm{~b}, 12 \%$ of the city scope has a high geotechnical vulnerability, mostly in northern Tehran and near the active North Tehran Fault. However, districts 22, 21, 5, 2 and $9(16 \%)$ are least vulnerable due to a decrease in PGA as a result of distance from fault and decrease in probability of hillside downfall as a result of decreased slope.

Finally, the existence of the Rey Fault and lineaments in south and southwestern Tehran shows that southern parts of the metropolitan including districts 20,18,15, 17, 11, 19 and $12(5 \%)$ will experience major damage in the case that the Rey Fault becomes active (Fig. 3c). One reason for this vulnerability is not only because southern parts of Tehran are near earthquake source but also because of the alluvial nature of these areas and high underground water level; PGA is high there. As a result, geotechnical vulnerability will increase when an earthquake occurs. In districts $22,4,5,2,1$, 3, 21 and 6, despite high slope in some parts, the low PGA and location on bedrock will decrease vulnerability.

\subsection{Structural indicators}

Structurally (Fig. 4a), a great part of districts 4, 12, 8, 11, 10, $14,7,5$ and $13(19 \%)$ is highly vulnerable. The reasons are as follows: districts 10,11 and 12 are the core of the city and very old. The construction time of some structures refer back to Qajar era (over 70 years ago). Districts 7, 8, 13 and 14 are host to migrations and districts 4 and 5 are villages which became a part of the city as time passed. Thus, masonry (brick 

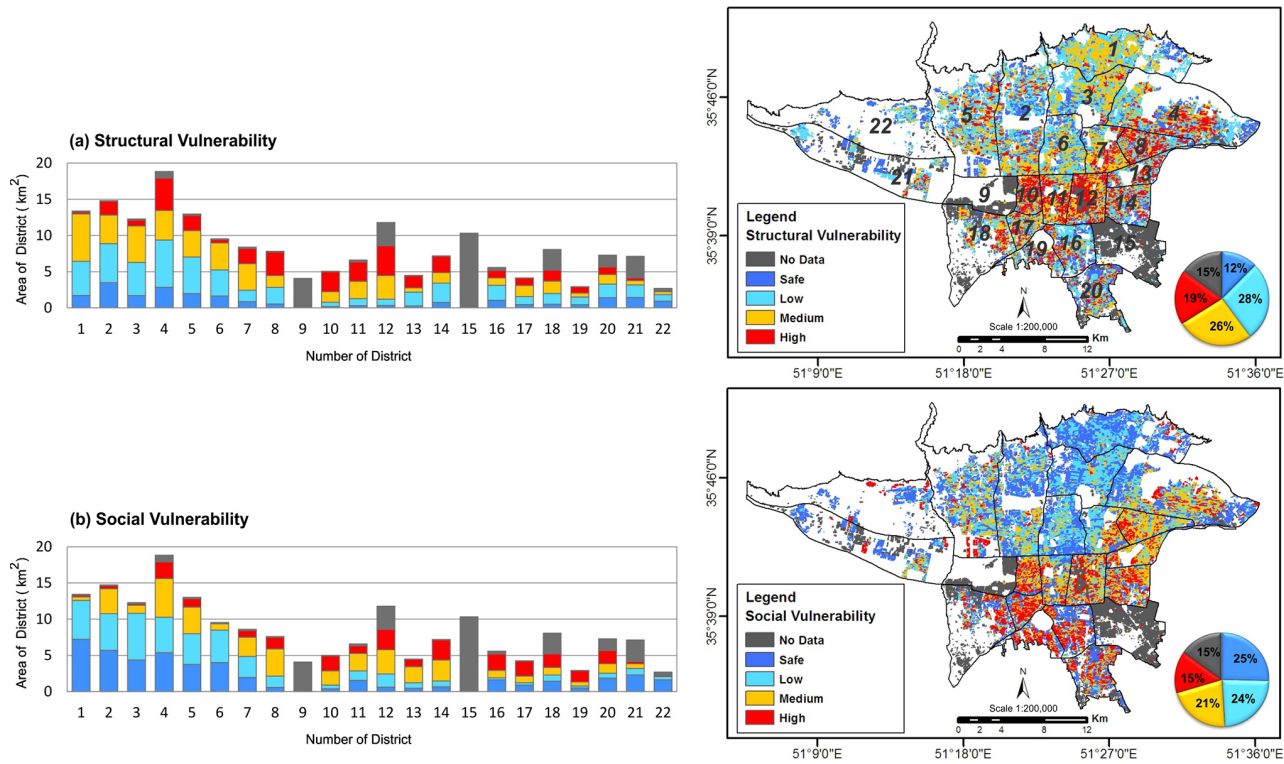
Number of Distric
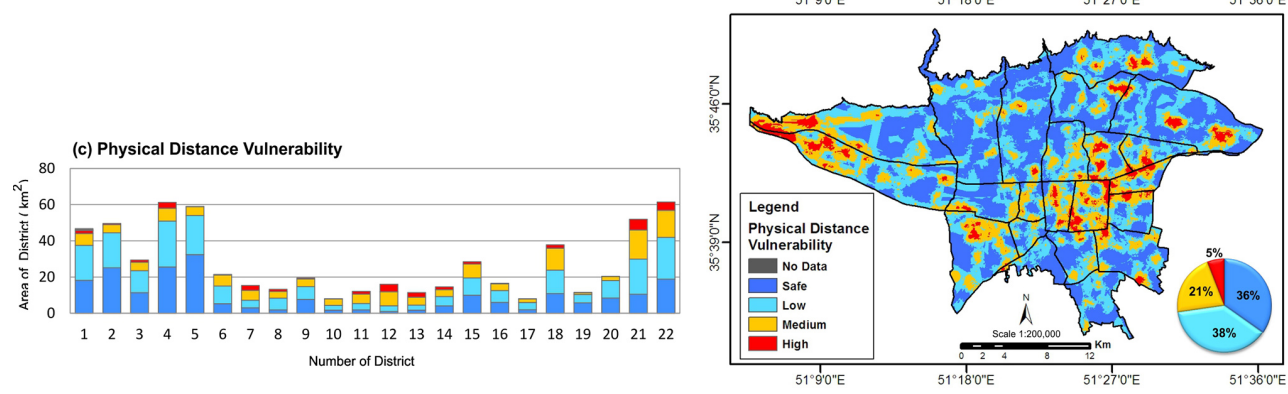

Figure 4. Tehran's seismic vulnerability map considering (a) structural, (b) social and (c) physical distance indicators.

and cement block or stone), sun-dried mud brick and wooden structures are common, leading to increased vulnerability of these areas. Another point is that these areas are host to people with lower incomes. Thus, cheap and low-quality structures as well as the lack of inspections have multiplied the structural vulnerability of the area.

However, a great part of districts 2, 4, 5, 3, 1, 6, 20, 21 and 22 are less vulnerable despite the existence of old and traditional areas, because there has been proper space for construction and affluent people have constructed structures in accordance with standard 2800 (BHRC, 2005). The result is newly built structures constructed with concrete and steel by professional engineers. In addition, low-density construction in these areas has helped reduce structural vulnerability.

\subsection{Social indicators}

The social vulnerability map (Fig. 4b) and extracted statistics show a considerable part of districts $12,14,4,16,10,17$, $18,19,20$ and $8(15 \%)$ is highly vulnerable. Due to low incomes, the residents live in small houses and, consequently, population density is high. Also, due to the high birth rate, children density increased in these areas (SCI, 2015).
Contrastingly, parts of districts $1,2,4,3,6,5$ and 7 are among the safest and least vulnerable areas since the residents have high incomes and bigger houses, which leads to a lower population density. Also, the new and almost modern context of the neighborhood has included fewer old people. The trend toward keeping distance from traditional culture and living a modern life among residents has made them less willing to marry and, as a result, to have children.

\subsection{Physical distance indicators}

Regarding Fig. 4c, the results show that $5 \%$ of Tehran areas are highly vulnerable with spread throughout the city. Yet old fabrics are more vulnerable compared to other parts. The reason for this could be a lack of access to freeways, the existence of high-voltage electrical power transmission lines and gasoline stations near houses and the distance from hospitals and police stations. Also, $21 \%$ of Tehran areas have medium vulnerability and $38 \%$ have low vulnerability. Also, in districts 5, 4, 2, 1, 22, 3 and 21 (36\%) the level of vulnerability is considerably low because of proper road access, ease of access to police stations, hospitals and emergency management centers, and distance from gasoline stations, highvoltage electrical power transmission lines and gas pipelines. 

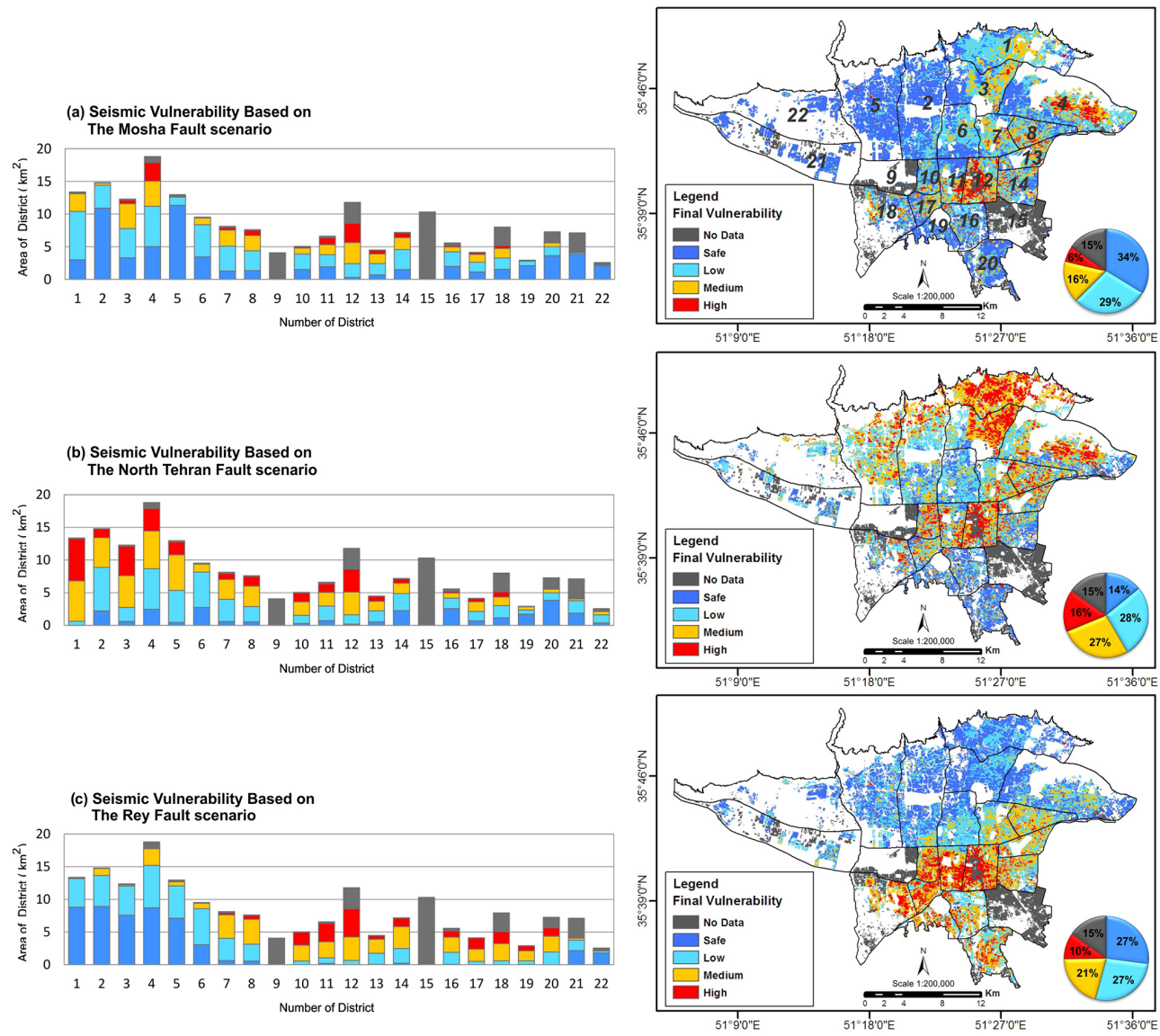

Figure 5. Seismic vulnerability map of Tehran related to three scenarios of (a) the Mosha, (b) the North Tehran and (c) the Rey faults.

\section{Discussion}

Tehran is located among a number of seismic faults with the high potential of earthquake occurrence. Its residential areas are highly vulnerable to earthquakes due to dense population, too many structures and violations of construction codes. Thus, in the case of an earthquake, the possibility of a severe damage will increase dramatically. Therefore, developing a seismic vulnerability map is a useful step to take in order to decrease the severity of a major earthquake impact in the area; construction of the vital structures such as hospitals and schools. In highly vulnerable areas can be limited and establishment of vital roads can be banned or subject to observing all earthquake engineering principles, seismic regulations and construction codes.

This study has extracted information layers in the form of geotechnical, structural, social and physical distance indicators according to three scenarios. Then, using AHP and GIS, three vulnerability maps have been developed for Tehran in case an earthquake occurs as a result of movements on the Mosha, North Tehran and Rey faults. The safe and vulnerable areas in each scenario are as follows.
1. The Mosha Fault scenario: in this scenario, the seismic vulnerability is low due to the distance of the fault from Tehran (around $36 \mathrm{~km}$ ). Thus, as in Fig. 5a, $6 \%$ of the city has high, $16 \%$ medium and $29 \%$ low vulnerability, and $34 \%$ is safe. Therefore, with regard to area, districts 12,4 and 11 have high vulnerability and districts 5, 2, 4, 21, 20, 6, 3, 1 and 19 are safer.

2. The North Tehran Fault scenario: regarding the North Tehran Fault, the northern part of the city will experience a great deal of damage since the fault is located on the northern margin of the city and a great population resides on the fault or its hanging wall. Therefore, as in Fig. 5b 16, 27 and $28 \%$ of Tehran areas have high, medium and low vulnerability, respectively, and $14 \%$ are safe. Thus, districts $1,3,4,12,5$, $8,10,2$ and 11 are highly vulnerable, while districts 20,6 , 16, 4, 14, 19 and 21 are safest.

3. The Rey Fault scenario: due to proximity of southern and central areas of the city to the Rey Fault and therefore high-intensity earthquakes, low quality and strength of structures, existence of old fabrics and dense population, the structural and social vulnerability is very high. However, in northern areas of the city, vulnerability is low due to better geotechnical, structural and social conditions than central 
and southern areas. Regarding the results (Fig. 5c), the level of seismic vulnerability in the scope of Tehran is $10 \%$ with high, $21 \%$ with medium and $27 \%$ with low vulnerability. $27 \%$ is also safe. Thus, districts $12,11,10,18,17,14,20$ and 16 have high vulnerability, and districts $2,1,4,3,5,6$, 21 and 22 are among the safest areas.

\section{Conclusions}

Developing a seismic vulnerability map is one of the most efficient methods for developing cities in seismically active areas. To this end, and since various factors are involved, four factors of geotechnical, structural, social and physical distance must be investigated simultaneously. For realizing this, developing a spatial GIS model and using the proper algorithm for categorization of factors and weighting them according to AHP seem vital. In this paper, three scenarios were investigated due to Tehran's location in the vicinity of the three active faults of Mosha, North Tehran and Rey. To cover the probable damages as a result of each fault's activity, each one is investigated separately with the following results:

1. The spatial GIS model is a proper tool for creating a database and developing a proper algorithm regarding the relationship among influential factors in determining the seismic vulnerability. The final outcome of this process will be more comprehensive and more close to reality.

2. After the identification of each area's vulnerability in each scenario, proper planning and paying close attention to low-cost methods such as increasing the potential for rescue, training, providing facilities for relocating densely populated areas and seismic retrofitting of available structures must be at hand.

3. In all scenarios, parts of central Tehran including districts 10,11 and 12 are vulnerable. Since these areas have included business centers, high priority must be given to them.

4. The lack of suitable data regarding districts 15 and 18 has led to failure in determining the seismic vulnerability. However, regarding low income of families, immigration and existence of geotechnical hazards in these areas, field studies must be performed to acquire needed data and determine the seismic vulnerability of these areas.

5. The inclusion of factors such as peak ground velocity, surface fault rupture, subsidence, landslide and liquefaction that have a determining role in seismic vulnerability makes the map closer to reality.

Edited by: O. Katz

Reviewed by: one anonymous referee

\section{References}

Adger, W. N., Brooks, N., Bentham, G., Agnew, M., and Eriksen, S.: New indicators of vulnerability and adaptive capacity, in: Rep. 7, Tyndall Centre for Climate Change Research, Norwich, UK, 128 pp., 2004.

Alinia, H. S. and Delavar, M. R.: Tehran's seismic vulnerability classification using granular computing approach, Appl. Geomat., 3, 229-240, doi:10.1007/s12518-011-0068-7, 2011.

Allen, M., Jackson, J., and Walker, R.: Late Cenozoic reorganization of the Arabia-Eurasia collision and the comparison of short-term and long-term deformation rates, Tectonics, 23, 1-16, doi:10.1029/2003TC001530, 2004

Almasri, M. N.: Assessment of intrinsic vulnerability to contamination for Gaza coastal aquifer, Palestine, J. Environ. Manage., 88, 577-593, doi:10.1016/j.jenvman.2007.01.022, 2008.

Altan, M., Özturk, F., and Ayday, C.: Preliminary earthquake risk management strategy plan of Eskisehir, Turkey by using GIS, in: 7th AGILE Conference on Geographic Information Science, 29 April-1 May 2004, Heraklion, Greece, 83-89, 2004.

Armaş, I.: Multi-criteria vulnerability analysis to earthquake hazard of Bucharest, Romania, Nat. Hazards, 63, 1129-1156, doi:10.1007/s11069-012-0209-2, 2012.

Armaş, I. and Gavriş, A.: Social vulnerability assessment using spatial multi-criteria analysis (SEVI model) and the Social Vulnerability Index (SoVI model) - a case study for Bucharest, Romania, Nat. Hazards Earth Syst. Sci., 13, 14811499, doi:10.5194/nhess-13-1481-2013, 2013.

Ashtari Jafari, M.: Statistical prediction of the next great earthquake around Tehran, Iran, J. Geodyn., 49, 14-18, doi:10.1016/j.jog.2009.07.002, 2010.

Åström, D. O., Forsberg, B., and Rocklöv, J.: Heat wave impact on morbidity and mortality in the elderly population: a review of recent studies, Maturitas, 69, 99-105, doi:10.1016/j.maturitas.2011.03.008, 2011.

Babayev, G., Ismail-Zadeh, A., and Le Mouël, J.-L.: Scenariobased earthquake hazard and risk assessment for Baku (Azerbaijan), Nat. Hazards Earth Syst. Sci., 10, 2697-2712, doi:10.5194/nhess-10-2697-2010, 2010.

Bac-Bronowicz, J. and Maita, N.: Mapping social vulnerability to earthquake hazards by using analytic hierarchy process (AHP) and GIS in Tehran City, available at: http://www.gisdevelopment.net/application/natural_hazards/ earthquakes/ma0777.htm (last access: 18 July 2014), 2007.

Bachmanov, D. M., Trifonov, V. G., Hessami, K. T., Kozhurin, A. I., Ivanova, T. P., Rogozhin, E. A., Hademi, M. C., and Jamali, F. H.: Active faults in the Zagros and central Iran, Tectonophysics, 380, 221-241, doi:10.1016/j.tecto.2003.09.021, 2004.

Berberian, M.: Active faulting and tectonics of Iran, in: Zagros, Hindu Kush, Himalaya: Geodynamic Evolution, edited by: Gupta, H. K. and Delany, F. M., Geodynamics Series 3, American Geophysical Union, Washington, D.C., 33-69, 1981.

Berberian, M. and Yeats, R. S.: Patterns of historical earthquake rupture in the Iranian Plateau, B. Seismol. Soc. Am., 89, 120 139, 1999.

Berberian, M. and Yeats, R. S.: Contribution of archaeological data to studies of earthquake history in the Iranian plateau, J. Struct. Geol., 23, 563-584, doi:10.1016/S0191-8141(00)001152, 2001. 
Berberian, M., Qorashi, M., Arzhangravesh, B., and Mohajer Ashjai, A.: Recent tectonics, seismotectonics, and earthquake-fault hazard study of the Greater Tehran region: contribution to the seismotectonics of Iran, Part V, Geol. Surv. of Iran, Rep. 56, Geological Survey of Iran, Iran, 1985.

BHRC (Building and Housing Research Center): Iranian Code of Practice for Seismic Resistant Design of Buildings, publication PNS-253, 3rd Edn., Building and Housing Research Center Iran, Iran, 135 pp., 2005.

Birkmann, J.: Risk and vulnerability indicators at different scales: applicability, usefulness and policy implications, Environ. Hazards, 7, 20-31, doi:10.1016/j.envhaz.2007.04.002, 2007.

Birkmann, J., Krings, S., and Renaud, F.: Assessment of vulnerability to floods at local level with a special focus on humanenvironmental systems and critical infrastructures, in: Proceedings of the 4th International Symposium on Flood Defense, 6-8 May 2008, Toronto, 2008.

Botero Fernández, V.: Geo-information for measuring vulnerability to earthquake: a fitness for use approach, $\mathrm{PhD}$ thesis, ITC, the Netherlands, 158 pp., 2009.

Buckle, P.: Assessing resilience and vulnerability in the context of emergencies: guidelines, Dept. of Human Services, Victoria, Melbourne, Australia, 20 pp., 2000.

Chakraborty, J., Tobin, G. A., and Montz, B. E.: Population evacuation: assessing spatial variability in geophysical risk and social vulnerability to natural hazards, Nat. Hazards Rev., 6, 23-33, 2005.

Chen, K., Blong, R., and Jacobson, C.: MCE-Risk: integrating multi-criteria evolution and GIS for risk decision-making in natural hazards, Environ. Modell. Softw., 16, 387-397, doi:10.1016/S1364-8152(01)00006-8, 2001.

Chen, M. F., Tzeng, G. H., and Ding, C. G.: Combining fuzzy AHP with MDS in identifying the preference similarity of alternatives, Appl. Soft. Comput., 8, 110-117, doi:10.1016/j.asoc.2006.11.007, 2008.

Cutter, S. L., Boruff, B. J., and Shirley, W. L.: Social vulnerability to environment hazards, Soc. Sci. Quart., 84, 242-261, doi:10.1111/1540-6237.8402002, 2003.

Dwyer, A., Zoppou, C., Nielsen, O., Day, S., and Roberts, S.: Quantifying social vulnerability: a methodology for identifying those at risk to natural hazards, Australian Government, Geoscience Australia, Rep. 2004/14, 101 pp., available at: http://www.ga. gov.au/image_cache/GA4267.pdf, last access: 21 June 2014.

Ebert, A. and Kerle, N.: Urban social vulnerability assessment using object-oriented analysis of remote sensing and GIS data. A case study for Tegucigalpa, Honduras, in: Proceedings of the XXIth ISPRS Congress, Beijing, China, 3-11 July 2008, XXXVII, 1307-1311, available at: http://www.isprs.org/ proceedings/XXXVII/congress/7_pdf/7_WG-VII-7/02.pdf (last access: 18 July 2014), 2008.

Ebert, A., Kerle, N., and Stein, A.: Urban social vulnerability assessment with physical proxies and spatial metrics derived from air- and spaceborne imagery and GIS data, Nat. Hazards, 48, 275-294, doi:10.1007/s11069-008-9264-0, 2009.

Flanagan, B. E., Gregory, E. W., Hallisey, E. J., Heitgerd, J. L., and Lewis, B.: A Social vulnerability index for disaster management, J. Homeland Security and Emergency Management, 8, 1547-7355, doi:10.2202/1547-7355.1792, 2011.
Fordham, M.: The place of gender in earthquake vulnerability and mitigation, in: Proceedings of Second EuroConference on Global Change and Catastrophic Risk Management: Earthquake Risks in Europe, 6-9 July 2000, Luxemburg, Austria, 2000.

Fothergill, A.: Gender, risk, and disaster, Int. J. Mass Emerg. Disast., 14, 33-56, 1996..

Fu, B., Lei, X., Hessami, K., Ninomiya, Y., Azuma, T., and Kondo, H.: A new fault rupture scenario for the $2003 M_{\mathrm{w}} 6.6 \mathrm{Bam}$ earthquake, SE Iran: insights from the high-resolution QuickBird imagery and field observations, J. Geodyn., 44, 160-172, doi:10.1016/j.jog.2007.02.002, 2007.

Gamper, C. D., Thöni, M., and Weck-Hannemann, H.: A conceptual approach to the use of Cost Benefit and Multi Criteria Analysis in natural hazard management, Nat. Hazards Earth Syst. Sci., 6, 293-302, doi:10.5194/nhess-6-293-2006, 2006.

Ghayamghamian, M. R. and Khanzade, K.: Buildings classification and determination of damage function for non-engineering in Bam city, J. Seismol. Earthq. Eng., 39, 2-10, 2008.

Ghodrati Amiri, G., Kazemiashtiani, V., and Razavian Amrei, S. A.: Seismic hazard analysis and obtaining peak ground acceleration (PGA) for Arak Region, Iran, Asian J. Civ. Eng., 11, 183-206, 2010.

Granger, K., Jones, T., Leiba, M., and Scott, G.: Community risk in Cairns: a multi-hazard risk assessment, Geol. Surv. of Australia, Rep. 1, available at: http://www.ga.gov.au/image_cache/ GA4164.pdf (last access: 21 July 2014), 19 pp., 1999.

Haki, Z., Akyüerek, Z., and Düezgüen, Ş.: Assessment of social vulnerability using geographic information systems: Pendik, Istanbul case study, in: 7th AGILE Conference on Geographic Information Science, Heraklion, Greece, 29 April-1 May, 413-423, available at: http://www.agile-online.org/Conference_ Paper/CDs/agile_2004/papers/4-3-4_Haki.pdf (last access: 18 July 2014), 2004.

Harp, E. L. and Wilson, R. C.: Shaking intensity thresholds for rock falls and slides: evidence from the 1987 Whittier Narrows and superstition hills earthquake strong-motion records, B. Seismol. Soc. Am., 85, 1739-1757, 1995.

Hellström, T.: Critical infrastructure and systemic vulnerability: towards a planning framework, Saf. Sci., 45, 415-430, doi:10.1016/j.ssci.2006.07.007, 2007.

Hessami, K., Koyi, H., Talbot, C. J., Tabasi, H., and Shabanian, E.: Progressive unconformities within an evolving foreland foldthrust belt, Zagros Mountains, J. Geol. Soc. London, 158, 969981, doi:10.1144/0016-764901-007, 2001.

Hessami, K., Nilforoushan, F., and Talbot, C. J.: Active deformation within the Zagros Mountains deduced from GPS measurements, J. Geol. Soc. Lond., 163, 143-148, 2006.

Hizbaron, D. R., Baiquni, M., Sartohadi, J., Rijanta, R., and Coy, M.: Assessing social vulnerability to seismic hazard through spatial multi-criteria evaluation in Bantul District, Indonesia, in: Conference of Development on the Margin, 5-7 October 2011, Bonn, Germany, 2011.

Holand, I. S., Lujala, P., and Rød, J. K.: Social vulnerability assessment for Norway: a quantitative approach, Norw. J. Geogr., 65, 1-17, doi:10.1080/00291951.2010.550167, 2011.

Ishita, R. P. and Khandaker, S.: Application of analytical hierarchical process and GIS in earthquake vulnerability assessment: Case Study of Ward 37 and 69 in Dhaka City, J. Bangladesh Inst. Plan., 3, 103-112, 2010. 
Jafargandomi, A., Fatemi Aghda, S. M., Suzuki, S., and Nakamura, T.: Strong ground motions of the 2003 Bam Earthquake, Southeast of Iran $\left(M_{\mathrm{W}}=6.5\right)$, B. Earthq. Res. I. Tokyo, 79, 47-57, 2004

Jibson, R. W.: Regression models for estimating coseismic landslide displacement, Eng. Geol., 91, 209-218, doi:10.1016/j.enggeo.2007.01.013, 2007.

Jibson, R. W., Harp, E. L., and Michael, J. A.: A method for producing digital probabilistic seismic landslide hazard maps, Eng. Geol., 58, 271-289, doi:10.1016/S0013-7952(00)00039-9, 2000.

JICA (Japan International Cooperation Agency) and CEST (Center for Earthquake and Environmental Studies of Tehran, Tehran Municipality): The Study on Seismic Microzoning of the Greater Tehran Area in the Islamic Republic of Iran, Final Report, Iran, 403 pp., 2000.

Keefer, D. K.: Landslides caused by earthquakes, Bull. Geol. Soc. Am., 95, 406-421, 1984.

King, D. and MacGregor, C.: Using social indicators to measure community vulnerability to natural hazards, Aust. J. Emerg. Manage., 15, 52-57, 2000.

Kuhlicke, C., Scolobig, A., Tapsell, S., Steinführer, A., and De Marchi, B.: Contextualizing social vulnerability: findings from case studies across Europe, Nat. Hazards, 58, 789-810, doi:10.1007/s11069-011-9751-6, 2011.

Landgraf, A., Ballato, P., Strecker, M. R., Friedrich, A., Tabatabaei, S. H., and Shahpasandzadeh, M.: Fault-kinematic and geomorphic observations along the North Tehran Thrust and Mosha Fasham Fault, Alborz mountains Iran: implications for fault-system evolution and interaction in a changing tectonic regime, Geophys. J. Int., 177, 676-690, doi:10.1111/j.1365246X.2009.04089.x, 2009.

Lantada, N., Pujades, L. G., and Barbat, A. H.: Vulnerability index and capacity spectrum based methods for urban seismic risk evaluation. A comparison, Nat. Hazards, 51, 501-524, doi:10.1007/s11069-007-9212-4, 2009.

Lee, S. and Pradhan, B.: Probabilistic landslide hazards and risk mapping on Penang Island, Malaysia, J. Earth Syst. Sci., 115, 661-672, doi:10.1007/s12040-006-0004-0, 2006.

Lee, S. and Talib, J. A.: Probabilistic landslide susceptibility and factor effect analysis, Environ. Geol., 47, 982-990, doi:10.1007/s00254-005-1228-z, 2005.

Mahdavifar, M. R., Solaymani, S., and Jafari, M. K.: Landslides triggered by the Avaj, Iran earthquake of 22 June 2002, Eng. Geol., 86, 166-182, doi:10.1016/j.enggeo.2006.02.016, 2002.

Mahdi, T. and Mahdi, A.: Reconstruction and retrofitting of buildings after recent earthquakes in Iran, Procedia Eng., 54, 127-139, doi:10.1016/j.proeng.2013.03.012, 2013.

Malczewski, J.: GIS and multi-criteria decision analysis, John Wiley, Toronto, 1999.

Malczewski, J.: GIS-based multi-criteria decision analysis: a survey of the literature, Int. J. Geogr. Inf. Sci., 20, 703-726, doi:10.1080/13658810600661508, 2006.

Martins, V. N., Silva, D. S., and Cabral, P.: Social vulnerability assessment to seismic risk using multi-criteria analysis: the case study of Vila Franca do Campo (São Miguel Island, Azores, Portugal), Nat. Hazards, 62, 385-404, doi:10.1007/s11069-0120084-x, 2012.

Moradi, M., Delavar, M. R., and Moshiri, B.: Sensitivity analysis of ordered weighted averaging operator in earthquake vulnerabil- ity assessment, in: Proceedings of SMPR 2013 Conference, 5-8 October 2013, Tehran, Iran, 277-282, 2013.

Nan, Z. and Hong, H.: Social vulnerability for public safety: a case study of Beijing, China, Chinese Sci. Bull., 58, 2387-2394, doi:10.1007/s11434-013-5835-x, 2013.

National Report of the Islamic Republic of Iran on Disaster Reduction; in: World Conference on Disaster Reduction, 18-22 January 2005, Kobe, Hyogo, Japan, available at: http://www.unisdr. org/2005/mdgs-drr/national-reports/Iran-report.pdf (last access: 24 July 2014), 2005.

Nazari, H.: Analyse de la Tectonique Récente et Active Dans l'Alborz Central et la Région de Téhéran: Approche Morphotectoniqueet Paléoseismologique, $\mathrm{PhD}$ thesis, University of Montpellier II, 247 pp., 2006.

Nefeslioglu, H. A., Sezer, E. A., Gokceoglu, C., and Ayas, Z.: A Modified Analytical Hierarchy Process (M-AHP) approach for decision support systems in natural hazard assessments, Comput. Geosci., 59, 1-8, doi:10.1016/j.cageo.2013.05.010, 2013.

Panahi, M., Rezaie, F., and Meshkani, S. A.: Seismic vulnerability assessment of school buildings in Tehran city based on AHP and GIS, Nat. Hazards Earth Syst. Sci., 14, 969-979, doi:10.5194/nhess-14-969-2014, 2014.

Peng, Y.: Regional earthquake vulnerability assessment using a combination of MCDM methods, Ann. Oper. Res., 15, 1-16, doi:10.1007/s10479-012-1253-8, 2012.

Plafker, G. and Galloway, J. P.: Lessons learned from the Loma Prieta, California earthquake of 17 October 1989, Geol. Surv. of US, Circular No. 1045, 56 pp., available at: http://pubs.usgs.gov/circ/ 1989/1045/report.pdf (last access: 20 June 2014), 1989.

Rashed, T. and Weeks, J.: Assessing vulnerability to earthquake hazards through spatial multi-criteria analysis of urban areas, Int J. Geogr. Inf. Sci., 17, 547-576, 2003.

Reid, C. E., O’Neill, M. S., Gronlund, C. J., Brines, S. J., Brown, D. G., Diez-Roux, A. V., and Schwartz, J.: Mapping community determinants of heat vulnerability, Environ. Health Persp., 117, 1730-1736, doi:10.1289/ehp.0900683, 2009.

Ritz, J. F., Nazari, H., Ghassemi, A., Salamati, R., Shafei, A., Solaymani, S., and Vernant, P.: Active Transtension in Central Alborz: a new insight of the Northern Iran-Southern Caspian Geodynamics, Geology, 34, 477-480, doi:10.1130/G22319.1, 2006.

Rocklöv, J., Ebi, K., and Forsberg, B.: Mortality related to temperature and persistent extreme temperatures: a study of causespecific and age-stratified mortality, Occup. Environ. Med., 68, 531-536, doi:10.1136/oem.2010.058818, 2011.

Saaty, T. L.: A scaling method for priorities in hierarchical structures, J. Math. Psychol., 15, 234-281, doi:10.1016/00222496(77)90033-5, 1977.

Saaty, T. L.: The analytic hierarchy process: Planning, Priority Setting, Resource Allocation, McGraw-Hill, New York, 287 pp. 1980.

Saaty, T. L.: The Fundamentals of Decision Making and Priority Theory with the Analytic Hierarchy Process, RWS Publications, Pitsburg, USA, 478 pp., 2000.

Safari, A. and Moghimi, A.: Geomorphologic assessment of urban development and vulnerability caused by landslide in mountainous hillsides of Tehran metropolis, J. Phys. Geogr. Res., 41, 5371, 2010.

Sarvar, H., Amini, J., and Laleh-Poor, M.: Assessment of risk caused by earthquake in region 1 of Tehran using the combina- 
tion of RADIUS, TOPSIS and AHP models, J. Civil Eng. Urban., $1,39-48,2011$

Schmidtlein, M. C., Deutsch, R. C., Piegorsch, W. W., and Cutter, S. L.: A sensitivity analysis of the Social Vulnerability Index, Risk Anal., 28, 1099-1114, doi:10.1111/j.1539-6924.2008.01072.x, 2008.

Schneiderbauer, S.: Risk and vulnerability to natural disasters-from broad view to focused perspective: theoretical background and applied methods for the identification of the most endangered populations in two case studies at different scales, $\mathrm{PhD}$ thesis, Freien Universität, Berlin, Germany, 121 pp., 2007.

SCI (Statistical Center of Iran): available at: http://www.amar.org. ir/Default.aspx?tabid=133, last access: 4 March 2015.

Seifolddini, F. and Mansourian, H.: Spatial-temporal pattern of urban growth in Tehran megapole, J. Geogr. Geol., 6, 70-80, doi:10.5539/jgg.v6n1p70, 2014.

Sella, G. F., Dixon, T. H., and Mao, A.: REVEL: a model for recent plate velocities from space geodesy, J. Geophys. Res., 107, ETG 11-1-ETG 11-30, doi:10.1029/2000JB000033, 2002.

Şen, Z.: Rapid visual earthquake hazard evaluation of existing buildings by fuzzy logic modeling, Expert Syst. Appl., 37, 56535660, doi:10.1016/j.eswa.2010.02.046, 2010.

Servi, M.: Assessment of vulnerability to earthquake hazards using spatial multi-criteria analysis: Odunpazari, Eskisehir case study, MS thesis, Middle East Technical University, Turkey, 94 pp., 2004.

Steinführer, A. and Kuhlicke, C.: Social vulnerability and the 2002 Flood, Country Report Germany (Mulde River), Leipzig, Rep. T11-07-08, 164 pp., available at: http://www.floodsite.net/html/ partner_area/project_docs/task_11_m11.3_p44_final.pdf (last access: 21 June 2014), 2007.

Suárez-Vega, R., Santos-Peñate, D.R., Dorta-González, P., and Rodríguez-Díaz, M.: A multi-criteria GIS based procedure to solve a network competitive location problem, Appl. Geogr., 31, 282-291, doi:10.1016/j.apgeog.2010.06.002, 2011.

Tatar, M., Hatzfeld, D., Abbassi, A., and Yamini Fard, F.: Microseismicity and seismotectonics around the Mosha fault (Central Alborz, Iran), Tectonophysics, 544-545, 50-59, doi:10.1016/j.tecto.2012.03.033, 2012.
Tavakoli, B. and Tavakoli, S.: Estimating the vulnerability and loss functions of residential buildings, Nat. Hazards, 7, 155-171, doi:10.1007/BF00680428, 1993.

Tchalenko, J. S., Berberian, M., Iranmanesh, H., Baily, M., and Arsovsky, M.: Tectonic framework of the Tehran region, Geol. Surv. of Iran, Rep. 29, available at: http://manuelberberian. com/Tchalenkoetal,1974-Tehran.pdf (last access: 18 June 2014), 1974.

Thieken, A. H., Kreibich, H., Müller, M., and Merz, B.: Coping with floods: preparedness, response and recovery of flood-affected residents in Germany in 2002, Hydrolog. Sci. J., 52, 1016-1037, doi:10.1623/hysj.52.5.1016, 2007.

Velasquez, G. and Tanhueco, R. M. T.: Social risk and disaster risk assessment, in: Know Risk, International Strategy for Disaster Reduction, United Nations, Tudor Rose, Geneva, 91-92, 2005.

Vernant, Ph., Nilforoushan, F., Hatzfeld, D., Abbassi, M. R., Vigny, C., Masson, F., Nankali, H., Martinod, J., Ashtiani, A., Bayer, R. Tavakoli, F., and Chéry, J.: Present-day crustal deformation and plate kinematics in the Middle East constrained by GPS measurements in Iran and northern Oman, Geophys. J. Int., 157, 381-398, doi:10.1111/j.1365-246X.2004.02222.x, 2004.

Wisner, B.: Turning knowledge into timely and appropriate action: Reflections on IADB/IDEA Program on Disaster Risk Indicators, IDB/IDEA Program of Indicators for Risk Management, National University of Colombia, Manizales, available at: http://idea.unalmzl.edu.co/documentos/ BenWisnerEMBarcelonaNov2003.pdf (last access: 21 June 2014), 2003.

Zebardast, E.: Constructing a social vulnerability index to earthquake hazards using a hybrid factor analysis and analytic network process (F’ANP) model, Nat. Hazards, 65, 1331-1359, doi:10.1007/s11069-012-0412-1, 2013. 